\title{
Una tipología de las profecías milenaristas
}

\author{
Enrique ROMERALES \\ Universidad Autónoma de Madrid \\ enrique.romerales@uam.es
}

\section{RESUMEN}

Muchas religiones, y especialmente las del Libro, incorporan una teología de la Historia de cuya meta y cumplimiento dan cuenta las profecías escatológicas. De entre éstas son máximamente recurrentes e impactantes las profecías milenaristas, que alertan de la inminencia del fin de los tiempos. Clasificamos las correspondientes experiencias proféticas en tres tipos: las de revelación-profeta, las de desciframientoexegeta, y las de cumplimiento-mesías, mostrando sus interrelaciones y señalando varios ejemplos. Concluimos analizando las reacciones alternativas ante los reiterados fracasos de estas profecías y haciendo algunas reflexiones filosóficas.

Palabras clave: Profecía, escatología, apocalipsis, eschaton, milenarismo, cumplimiento, fin de los tiempos.

\section{A Typology of Millenarian Prophecies}

\begin{abstract}
Many religions, specifically the ones of the Book, involve a theology of History which goal and fulfillment is accounted for in eschatological prophecies. The millenarian prophecies, which alert about the imminence of the end of times, are the most recurrent and shocking among them. The corresponding prophetic experiences are classified into three kinds: revelation-prophet, deciphering-interpret and fulfillment-messiah, putting forward their interrelations and mentioning various examples. We conclude analyzing the different reactions facing repeated failures of these prophecies and making some philosophical reflections.
\end{abstract}

Keywords: Prophecy, eschatology, apocalypse, eschaton, millenarianism, fulfillment, end of times.

SUMARIO: 1. Supuestos. 2. Tipología. 2.1. Revelación-profeta. 2.2. Desciframiento-exegeta. 2.3. Cumplimiento-mesías. 3. Reacciones alternativas ante el incumplimiento profético. 
A diferencia de la filosofía, toda teología resuelve las grandes cuestiones acerca de la historia (su sentido, su meta o su cierre) de un modo afirmativo: hay sentido, progreso (o degeneración previa al Armagedón), destino, cumplimiento. La teología de la historia niega dos opciones abiertas para la filosofía: a) que aun no habiendo meta o destino algunos la historia se desarrolle siguiendo un patrón o una ley de forma cíclica. Cabría entonces desentrañar este nomos, pero no existiría propiamente un telos de la historia; b) que la historia simplemente se desarrolla; que la humanidad sencillamente evoluciona, como lo han hecho anteriormente innumerables especies y el propio planeta, pero que no cabe hablar de progreso en la medida en que ello incluya una meta, o sea: un destino y un final entendido no como interrupción, sino como culminación y cumplimiento.

Todas las religiones del Libro llevan incorporada una teología de la historia, aunque con importantes variaciones. Si bien el significado y sentido de cada teología de la historia suele ser manifiesto, lo más problemático es su justificación, su credibilidad. Nada puede dotar de mejores credenciales a la idea de que efectivamente hay un futuro determinado, y por ende un destino y, en definitiva, una culminación, que el poder de profetizar, que desvela y anticipa (total o parcialmente) ese futuro. El cumplimiento de la profecía aparecerá entonces como garantía de la veracidad.

De entre los tipos de profecías, ninguno más contundente, más pregnante y teológicamente más relevante que las profecías escatológicas referentes al final de la historia o de los tiempos y al subsiguiente mundo del porvenir. Una primera diferencia ha de establecerse entre las profecías que indican un final de la historia, es decir, del orden mundial establecido tal y como lo conocemos, al que sucederá un orden mundial distinto, definitivo y por intervención sobrenatural (p.ej. la restauración del Reino de Israel en Sión, bajo el mandato de Jesucristo, y el sometimiento de todas las naciones), y aquellas que dibujan un final de los tiempos, entendiendo por tal el fin del planeta Tierra o incluso del universo entero ${ }^{1}$ y el subsiguiente inicio de una vida espiritual celestial eterna. Si bien en ambos casos hay una ruptura con el eón presente, en el primero el Armagedón dará lugar a una historia nueva y distinta de la humanidad, mientras que en el segundo dará fin a la Historia misma y paso a la eternidad. Sin embargo, la distinción no siempre es nítida, pues muchas profecías entremezclan elementos de una y otra opción. En adelante emplearemos el término eschaton para referirnos indistintamente a profecías que anticipan el final, sea de la historia, sea del del tiempo.

Estas profecías escatológicas anticipan un futuro que se representará como más o menos específico y más o menos próximo. Cuando las profecías sobre el final de los tiempos y/o el mundo/reino/estado del porvenir (llámesele Reino de Dios, Vida eterna, Cielo...) implican inminencia provocan el desasosiego o incluso la alarma gene-

\footnotetext{
${ }^{1}$ Nosotros distinguimos entre el final de la vida humana sobre la Tierra -p.ej. si un meteorito gigante provocara un invierno nuclear- el final de la Tierra como planeta -cuando el Sol se convierta en una estrella gigante roja y engulla nuestro planeta- y el final del Universo, que estimamos muy posterior a ambos acontecimientos. Pero para los antiguos -salvo excepciones ajenas al monoteísmo- la Tierra era el centro y el eje del Universo, de modo que su destrucción comportaba la del Universo entero.
} 
ralizada, y la conminación al arrepentimiento y a la conversión. Podemos denominar a este tipo de profecías 'milenaristas' en un sentido laxo.

Hay que resaltar que en sentido estricto, empero, 'milenarismo' se refiere a las profecías que siguiendo el Apocalipsis de Juan retratan un inminente final de la historia y el comienzo de una nueva era, especie de vuelta al Paraíso con la presencia de Dios o de sus representantes incluida, que durará mil años, tras la cual un Juicio Universal sobre vivos y muertos dará paso a la eternidad (final, este sí, del tiempo y de la historia) $)^{2}$. No obstante, en sentido laxo se denomina asimismo milenaristas a las profecías que hablan genéricamente del final, sea de los tiempos o de la historia, y lo anuncian como algo inminente, haya o no un subsiguiente reinado interino milenario de paz y armonía previo a la consumación final ${ }^{3}$.

La historia de las religiones nos enseña numerosas y reiteradas muestras de profecías referentes al final de los tiempos o de la historia. Estas profecías emanan de un supuesto conocimiento referente al eschaton obtenido por algún tipo de revelación divina. Analizaremos por turno los presupuestos de tal conocimiento, los tipos de experiencias proféticas milenaristas y las reacciones cuando la profecía fracasa. Asimismo lo ilustraremos con diversos ejemplos históricos paradigmáticos.

\section{SUPUESTOS}

No nos ocupamos aquí con el asunto del conocimiento de un final de los tiempos entendido como el final natural del universo, de nuestra galaxia o siquiera de nuestro sistema solar, planteado siempre a muy largo plazo y por el curso natural de los acontecimientos. De este asunto se ocupa la cosmología científica y, aunque hay actualmente varias hipótesis alternativas acerca de cómo acabará nuestro universo, prácticamente todas coinciden en una cosa: que falta mucho tiempo para ello -medido en miles de millones de años-. También coinciden en que habrá un final, sea por un Big-crunch o por una expansión disgregadora lenta (como se pensaba hasta hace poco), o por un «destripamiento» brusco o por un «encuentro» con un universo paralelo ${ }^{4}$.

\footnotetext{
2 Para el sentido estricto de milenarismo, véase J. J. Collins, The Apocalyptic Imagination: An Introduction to the Jewish Matrix of Christianity, $2^{\mathrm{a}}$ ed. Cambridge, 1998, pp. 280s. En español puede consultarse L. Vegas Montaner, «La apocalíptica judía», Hesperia. Culturas del Mediterráneo 6 (2007), pp. 207-238. B.R. Wilson distingue entre el pre-milenarismo -la creencia en que la Segunda Venida antecederá al reino de los mil añosy el pos-milenarismo - la creencia en que el reino de los mil años se alcanzará mediante los solos esfuerzos humanos, y que la Segunda Venida acaecerá al final del reino (Cfr. B.R. Wilson: «Millenialism», en International Encyclopedia of the Social \& Behavioral Sciences, Nueva York, Elsevier, 2004, pp. 9881s.).

${ }^{3}$ Así lo entiende p.ej. H. Schwarzt, en el artículo «Millenarianism. An Overview» de la Encyclopedia of Religion, New York, Macmillan, 1987, Vol. IX, pp. 6028-6038).

${ }^{4}$ El físico Pedro González Díaz apunta a una posible desaparición del universo por un «desgarrón» al final del proceso de expansión acelerada, en el que todo se escinde de todo, quedando sólo vacío (cfr. su artículo, «La energía fantasma y el futuro del universo», Investigación y ciencia, 357, junio 2006, p. 55). Otros modelos indican un final por consumición de toda la energía, cuando vayan quedando sólo agujeros negros y estrellas enanas rojas. Pero todos los modelos, incluidos los cíclicos, convienen en que faltan entre decenas de
} 
Nuestro asunto es el final sobrenatural de la historia, del tiempo para la humanidad tal y como la conocemos, y debido a una irrupción e intervención divina. Que podamos tener acceso a un conocimiento acerca de este final de los tiempos presupone lo siguiente: a) la historia tiene no solamente una evolución sino una direccionalidad y un sentido. b) Hay una meta de esa historia. c) Tanto el sentido como la meta pueden ser desentrañados por el ser humano, al menos bajo ciertas condiciones y por ciertos sujetos privilegiados - privilegiados bien por sus dotes proféticas, por sus capacidades intelectivas o por haber sido ungidos o escogidos por la divinidad-. A lo anterior, las profecías milenaristas añaden que: d) la meta está próxima. En algunos casos, se supone que: e) se ha podido descifrar (o, menos frecuentemente, que le ha sido revelada al profeta) la fecha concreta del final.

Que la humanidad tiene una «historia», que cambia, que se desarrolla y evoluciona, es algo demasiado obvio para ser cuestionado. Que esta evolución tenga un sentido, una direccionalidad, es mucho más discutible, sobre todo si pensamos que es una direccionalidad impuesta previamente y por ende desde una instancia ajena a la humanidad misma. Este sentido trascendente de la historia puede concebirse en términos de una cierta degeneración (como -según una interpretación frecuente- en las edades del hombre de los Trabajos y los días de Hesíodo), en términos de un progreso (sea intelectual, moral, material, o todo ello, como pensaban los ilustrados), o en términos de etapas por las que velis nolis hay que pasar, sin que tal sucesión tenga por qué implicar globalmente progreso o degeneración. Las concepciones teológico-religiosas de la historia entienden habitualmente el sentido en términos de avance, no necesaria ni frecuentemente moral o religioso, sino de marcha hacia el cumplimiento, hacia el destino. Si bien, es cierto que en muchas religiones aparece la idea de que tras la llegada del mesías/avatar/divinidad encarnada la humanidad tiende a olvidarse de su mensaje y a degradarse, por lo cual es menester que la divinidad se encarne periódicamente. Así ocurre con los «budas del porvenir», como el boddhisattva Maitreya que, según el budismo Mahayana, se convertirá en el próximo buda histórico tras el de nuestra era, Siddharta Gautama (dentro de unos treinta mil años según los cálculos más conservadores y de cinco mil millones de años según los menos).

Si hay un sentido, una direccionalidad, tiene que existir tanto un inicio como un final. Este final es entendido como destino y meta. Puede interpretarse de diversos modos: como una realización de las potencialidades humanas, o como un agotamiento, como un quedar exhausto del ser humano en sus capacidades intelectuales, morales, estéticas y religiosas. Es incluso frecuente interpretarlo como un culmen de la degradación espiritual y moral (p.ej. 1 Hen 91, 5-9), que presagia y justifica el juicio y castigo divino. Tanto el sentido de esta historia como su meta pueden ser conocidos gracias a algún tipo de revelación. Esta revelación procede directa o indirectamente de seres sobrenaturales superiores, o de Dios mismo, que conocen lo que a nosotros nos está por naturaleza vedado: el futuro. Esto implica no sólo que el futuro está escrito, sino que la

miles de millones de años y billones para ese final. En cambio, el fin de la vida humana sobre la tierra sí podría suceder en cualquier momento de forma natural: porque se estrellara un meteorito gigante, $\mathrm{o}-$ con menor plausibilidad- por una enorme tormenta solar. 
divinidad quiere que se nos transmita su conocimiento, sea a toda la humanidad o sólo a los elegidos (el pueblo escogido, los justos, los fieles a la doctrina, etc.).

Un rasgo distintivo de muchas profecías, aunque ni mucho menos de todas, es la inminencia de tales acontecimientos, y por consiguiente lo imperioso de un cambio radical de nuestra actitud y forma de vida. La llamada adquiere forma de alarma general, porque el tiempo se agota. Hay otro tipo de profecías que anuncian el eschaton para un tiempo remoto e indefinido. Por ejemplo, Isaías $(65,17)$ anuncia la creación de un nuevo cielo y una nueva tierra, o Malaquías $(4,5)$ la vuelta de Elías como nuncio del Mesías. Así mismo, los judíos siguen a la espera del Mesías, o los musulmanes chiíes a la espera del Mahdi. Aquí nos ocuparemos sólo con las profecías escatológicas del primer tipo, las que indican un tiempo muy próximo -sea más o menos definido- porque son las que pueden falsarse -y de hecho se han falsado-.

De entre estas profecías, algunas han tenido la osadía de determinar con mayor o menor precisión la fecha exacta del acaecimiento, o los límites temporales inferior y superior para su cumplimiento. Otras, con más frecuencia, se han contentado con proclamar la inminencia. Asimismo, la gran mayoría describen con detalle -incluso con todo lujo de detalles- los acontecimientos finales, e incluso sus señales antecedentes, sea de manera simbólica y alegórica, como en el Libro de las visiones (o de los sueños) dentro del Libro primero de Henoc ${ }^{5}$, o literal, como Pablo en 1 Tes 4, 13.

La palabra 'milenarismo' deriva del Apocalipsis y, si bien en sentido laxo hemos visto que designa a todas aquellas profecías del final de los tiempos que subrayan su carácter inminente, en un sentido más estricto podemos considerar que las profecías específicamente milenaristas describen la instauración del Reino de Dios -o su equivalente mesiánico- en dos fases. En una primera, tras numerosas catástrofes históricas de carácter socio-económico, político y militar, pero con frecuencia también meteorológicas, geológicas e incluso astronómicas, finalizará el eón presente y se instaurará el Reino de Dios en la Tierra (presidido por Jesucristo, escudado por sus ángeles, y acompañado de los apóstoles, los santos y los mártires, etc.), que durará mil años (al igual que cada día de la creación dura mil años humanos), y será una suerte de restitución del Paraíso ${ }^{6}$. Luego advendrá el Juicio Final, la derrota del demonio y la consumación definitiva de los tiempos, que dará paso a la segunda y definitiva fase (Apocalipsis de Juan). Fase sobre la que, por cierto, apenas hay nada que decir, dado que la consumación del tiempo, la entrada en la eternidad, comporta la desaparición de los sucesos, de los eventos, y por ello de toda posible narración de los mismos.

${ }^{5} 1$ Hen 83-90. El Libro 1 de Henoc o Henoc etiópico es una amalgama de textos de diversos autores, presumiblemente escritos entre los siglos III a.C. y I d. C. y refundido probablemente a finales del siglo I de nuestra era, que tuvo mucha influencia en el Nuevo Testamento, en los primeros apologistas cristianos y en varios Padres de la Iglesia hasta el siglo IV. Pero existen además otros dos libros distintos «de Henoc»: el Libro de los secretos de Henoc, conservado solamente en eslavo arcaico, y el Libro hebreo de Henoc, ambos posteriores al primero y que no tuvieron una influencia semejante en el cristianismo. Cfr. A. Díez Macho: Apócrifos del Antiguo Testamento, Vol. IV, Madrid, Cristiandad, 1984.

${ }^{6}$ Aunque con diferencias importantes. P.ej. en Isaías 65,19 se nos dice que no habrá sufrimiento, dolor, enfermedad, injusticia ni disputas; pero sí muerte -tras una asegurada longevidad-a diferencia de lo que ocurría en el Paraíso terrenal. 
Las profecías milenaristas en sentido amplio pueden pronosticar, en cambio, un único acontecimiento final (o ser ambiguas al respecto), un cataclismo que implica el fin de la Tierra y la consumación en el Cielo (1 Cor 15, 51). Sin embargo, no siempre está claro en una profecía si se trata de una consumación en dos fases o en una única. La diferencia de versiones entre Pablo y Juan de Patmos en el cristianismo ha sido en buena parte fuente de esta confusión. La expresión de Isaías, retomada por el Apocalipsis, de un «nuevo cielo» y una «nueva tierra» es lo suficientemente ambigua para no dejar claro si se trata de una regeneración-restauración de ambos, o de una liquidación de los existentes que da paso a la creación de realidades nuevas y distintas. En todo caso persiste la dualidad cielo-tierra (no es el cielo lo único existente), lo que suscita numerosos interrogantes: ¿quiénes habitarán el uno y quiénes la otra? ¿Es la Nueva Tierra sólo el lugar del infierno de los pecadores? Si Dios va a habitar la Nueva Jerusalén que está en la Nueva Tierra junto con todos los santos ¿quedará vacío el Nuevo Cielo? En cualquier caso: ¿por qué hace falta un cielo «nuevo»?; ¿acaso también allí -en el cielo antiguo- hay «cuentas que ajustar»? ${ }^{7}$

Volviendo a los dos tipos de profecías milenaristas, las primeras -las milenaristas stricto sensu- entienden el final de la historia en términos de restauración de una Edad dorada, del Paraíso que se perdió; las segundas, empero, en términos de una definitiva retribución a los justos por sus inmerecidos sufrimientos. Ambas incluyen el castigo de los malvados, sea enviándolos al infierno, fulminándolos o simplemente no resucitándolos. Según se subrayen los horrores del cataclismo final o más bien las bondades de la restauración/restitución subsiguiente prevalecerán respectivamente el elemento armagedónico o el utópico. En general, los profetas han tendido a ocuparse más del primer aspecto, pues es más plástico e impactante, y tiene un fuerte carácter dinamizador; el bienestar o incluso la felicidad no pueden movilizar tanto $\mathrm{y}$ tan deprisa como el pánico.

Como señalé, aquí tomaremos el término 'milenarista' en sentido amplio, y nos centraremos en todas aquellas profecías que señalan que el eschaton es inminente, en una o en dos fases, con o sin fecha concreta, descrita con mucho, poco o ningún detalle, presentada de manera más literal o más simbólica. Dejaremos fuera las profecías de un final o acontecimiento específico, pero lejano, como la de Maitreya (el buda del porvenir), o el Mahdi.

\section{TIPOLOGÍA}

Todas las profecías escatológicas comportan dos tipos distintos de personajes. En primer lugar el profeta escatológico, que es quien anticipa el eschaton, y en se-

\footnotetext{
${ }^{7}$ En $A p$ 21, se nos dice que la Nueva Jerusalén descenderá del cielo a la tierra, y Dios con ella en calidad de esposo, y ahí (o sea, en la Nueva Tierra) morarán felices por siempre los justos con Dios. Pero no habrá sol ni luna, ni día ni noche, pues la gloria de Dios iluminará todo permanentemente. En tal caso ¿Qué clase de «tierra» es esa? Más bien parece que hay que interpretarlo espiritualmente, como un lugar celestial. Pero entonces, ¿por qué hay además un Cielo Nuevo?
} 
gundo lugar el mesías $^{8}$, que es quien lo cumple. En las profecías milenaristas pueden ocurrir dos cosas: o bien el mismo profeta que anticipa el futuro avisa también de su inminencia -como veremos más adelante con Joseph Smith o Dorothy Martin-o bien -y con más frecuencia- la inminencia viene anunciada en un tiempo ulterior por un tercer tipo de personaje, el intérprete: un erudito y exegeta que ha desentrañado la fecha del eschaton que se hallaba cifrada en los textos del profeta ${ }^{9}$. Según que el protagonismo de los acontecimientos recaiga en uno u otro de los tres tipos de personaje mentados, tenemos tres tipos de experiencias milenaristas ${ }^{10}$ :

1) Cuando el pronosticador tiene una revelación (sea mediante una visión de los acontecimientos futuros, mediante una comunicación verbal, o mediante una suerte de «viaje» extra-mundano), tenemos entonces un profeta escatológico. La clave es que un profeta siempre anticipa el futuro.

2) Cuando el pronosticador logra descifrar el código -o desentrañar los símbolosde un mensaje sobre el final de los tiempos oculto en un determinado texto sagrado. Tenemos entonces un descrifrador o exegeta.

3) Cuando alguien es reconocido (o se presenta a sí mismo) como mesías, que o bien va a realizar él mismo el cumplimiento del final de los tiempos, o bien es el heraldo de su inminencia. En este caso, de una profecía que permanecía sin especificar en cuanto a la fecha se avisa que el tiempo se ha cumplido, que ha llegado la hora o

\footnotetext{
8 «Mesías» tiene diversos significados y matices en los diversos textos y períodos históricos: ungido, rey, sacerdote, salvador, juez, enviado por la divinidad o encarnación de la divinidad (cfr. nota 12). Aquí lo empleo como contrapunto dialéctico de un profeta escatológico: mesías es quienquiera que va a cumplimentar el eschaton anticipado por el profeta, donde «cumplimentar» deja un ámbito de vaguedad que suele incluir varios de los siguientes eventos: vencer definitivamente al demonio, someter a las naciones, desencadenar el proceso del final de la historia, provocar el Armagedón, causar el cataclismo cósmico, resucitar a los muertos, arrebatar a los justos al cielo, abrir el Juicio Final, ser nuncio de la venida del mismo Dios, aparecer y manifestarse como encarnación de Dios.

${ }^{9}$ El intérprete erudito puede ser no solamente un teólogo, sino un científico de prestigio, como en el caso de Newton. Pero Newton, que creía firmemente que en la Biblia se hallaba en clave simbólica la fecha del eschaton, no fue un milenarista en nuestro sentido, pues sus cálculos exegéticos sobre Daniel y el Apocalipsis pretendían probar, contra los numerosos milenaristas del momento -como Joseph Mede o el obispo de Worcester William Lloyd- que el eschaton no era inminente, sino que no acaecería hasta comienzos del tercer milenio. De hecho, como ocurrió luego con William Miller, Newton nunca fijó una fecha exacta para el final de los tiempos, sino fechas para los umbrales mínimo y máximo entre los cuales podía acaecer tal evento; fechas que, además, modificó en varias ocasiones y no quiso divulgar ni publicar, pues ¿qué sentido tendría difundir algo que iba a ocurrir cuatro o cinco siglos después? Cfr. S.D. Snobellen, «A Time and Times and the Dividing of Time: Isaac Newton, the Apocalypse and 2060 A.D.», Canadian Journal of History, XXVIII, diciembre 2003, sec. V. Así mismo, Jan Wojcik ha mostrado que es plausible que Robert Boyle, pese a lo que habitualmente se supone dada su estrecha relación con el entusiásticamente milenarista círculo de Samuel Hartlib, tampoco creyera en la inminencia del final de los tiempos (Cfr. «Robert Boyle, the Conversion of the Jews, and Millenial Expectations», en J.E. Force \& R.H. Popkin [eds.], The Millenarian Turn: Millenarian Contexts of Science, Politics and Everyday Anglo-American Life in the Seventeenth and Eighteenth Centuries, Dordrecht, Kluwer, 2010, pp. 55-66).

${ }^{10}$ No se trata en realidad de tres tipos de profecías, pues sólo los personajes del primer tipo son profetas: sólo ellos tienen experiencias perceptivas extrasensoriales (visiones, audiciones, sueños, etc.), atribuidas a potencias sobrenaturales, que visualizan o relatan el eschaton. Y sólo el profeta escatológico y el intérprete pronostican, pues un mesías se limita a cumplir la prognosis.
} 
que está a punto. La clave es que el enviado cumple un destino en el presente. Tenemos, entonces, un mesías.

El mesías es la contrapartida complementaria del profeta: se le puede reconocer como tal sólo y en la medida en que ha sido previamente anunciado; porque se le espera, y porque hay señales inequívocas de cumplimiento (nace en tal o cual lugar particular, de determinada estirpe, con frecuencia de una virgen, acompañado por señales meteorológicas, geológicas o celestes extraordinarias, está llevando a cabo tal o cual misión, alguien con autoridad espiritual en la comunidad lo reconoce como tal y realiza milagros públicos que son signos inequívocos de su carácter sobrenatural). Tenemos, pues, tres tipos de caracteres implicados: profeta escatológico, exegeta y mesías.

Mientras que el exegeta o «descifrador» es un caso aparte -y de una talla religiosa inferior-, pues se trata normalmente de un erudito: un estudioso de los textos sagrados (en ocasiones esotéricos), un cabalista, un teósofo, incluso un filósofo o un científico que ha descifrado por sí mismo tras largo esfuerzo un mensaje oculto acerca del final de los tiempos (normalmente se trata de su fecha, no del detalle, que ya aparece descrito en los correspondientes textos sagrados apocalípticos escatológicos), la distinción entre el profeta escatológico y el mesías no siempre es nítida. Hay casos en que quien recibe una revelación profética es elevado acto seguido a la categoría mesiánica $\left(\mathrm{Henoc}^{11}\right)$, o casos en que al protagonista se le atribuyen esas diversas funciones en diferentes textos (Melquisedec ${ }^{12}$ ), porque la figura de quien anuncia el mensaje del inminente final de los tiempos puede transmutarse y convertirse asimismo en la vía de salvación y en co-realizador de este destino. Y a la inversa, quien se presenta, o con mayor frecuencia es reconocido y presentado por otro, como mesías (salvador, culminador de los tiempos) a su vez profetiza la inminencia de este final. Así ocurre en el caso de Jesús de Nazaret, quien anuncia la inminencia del final y que será él quien lo protagonizará, aunque no entra en detalles acerca de cómo va a acontecer ese final. La razón de fondo es la siguiente: lo característico del milenarismo es que la inminencia atribuida al cumplimiento de la profecía difumina la distinción entre presente y futuro; los acontecimientos se están ya empezando a cumplir a la vez que se están profetizando. Examinemos a continuación ejemplos de los tres tipos.

${ }^{11}$ En lo que suele ser considerado una interpolación ajena al autor de las Parábolas, Henoc se transforma en Hijo del Hombre tras ser ascendido al Cielo $(1$ Hen 71, 14). Esta tradición es la que se desarrolla en el posterior Libro hebreo de Henoc (3 Hen 6, 3). Cfr. A. Díez Macho, op. cit. p. 30.

12 Sal 110. F. García Martínez afirma: «en el judaísmo pre-cristiano se había desarrollado ya la idea de un agente celeste de la salvación escatológica. En Qumrán, junto al «mesías-rey» descendiente de David y al «mesías-sacerdote» descendiente de Aharón, se esperaba también al final de los tiempos la acción salvadora de un «mesías-celeste». Que la ampliación de la idea de «mesías» para que pudiera incluir una figura celeste se halle atestiguada por vez primera en el caso de Melquisedec no parece accidental. El Melquisedec de Gen 14 era rey y sacerdote, y en cuanto tal un perfecto sujeto de la «unción». Y puesto que el Sal 110 lo presenta como un sacerdote celeste en el contexto del juicio divino, era fácil el desarrollar sus funciones para que incluyeran las funciones tradicionalmente atribuidas al «mesías»: aportar la salvación escatológica, destruir los ejércitos de Belial, realizar el juicio final e introducir la era de paz eterna para los elegidos.» («Las tradiciones sobre Melquisedec en los manuscritos de Qumrán», Biblica, Vol. 81, 2000, p. 79). Melquisedec aparece con dotes proféticas en textos no canónicos, como en el manuscritos de Qumrán 11QMelch, donde el profeta escatológico es asimismo mesías (ibídem p. 81). 


\subsection{REVELACIÓN-PROFETA}

El modelo de referencia por antonomasia es el Apocalipsis de Juan. Al autor le es concedida la visión de los acontecimientos finales. No hay fecha concreta, pero es algo próximo, que se describe con todo lujo de detalles. Señalemos otros tres casos paradigmáticos.

Dentro del complejo Libro 1 de Henoc, el denominado Apocalipsis de las semanas, tras la correspondiente periodización de la historia ya acaecida en siete «semanas», narra los acontecimientos finales, incluida una periodización de la meta-historia. El autor se ubica al final de la séptima «semana», con la que acaba la historia ordinaria. Pero restan tres «semanas» en las que, respectivamente, los justos juzgarán y ejecutarán sentencia sobre los injustos, tal juicio se revelará al mundo entero (que se preparará para la destrucción), y en la décima acaecerá el Juicio Final, despareciendo el viejo cielo y creándose el nuevo. A partir de entonces se instaurará una eternidad de paz, bondad y justicia ${ }^{13}$. Podemos considerar milenarista al autor porque es inminente el final de la historia (ordinaria), y con ello el inicio del proceso hacia el final de los tiempos. Pero lo significativo es que entre ese inicio del fin de los tiempos y el acaecimiento del final mismo existe un período que -y esto es lo más original- no consiste en un estado o situación uniforme (el millenium) de tipo ideal o paradisíaco, sino en un dilatado proceso en tres fases con sus correspondientes acontecimientos.

Casi dos milenios después, Joseph Smith, el fundador de la Iglesia de Jesucristo de los Santos de los Últimos Días, más conocidos como «mormones», pasó por etapas de revelaciones continuas $-\mathrm{y}$ a la carta ${ }^{14}-$ en algunas de las cuales se muestran sus dotes proféticos:

Pude haber dado una traducción más clara de esto, pero para mi objetivo tiene suficiente claridad tal como está. Basta saber, en este caso, que la tierra será heri$d a$ con una maldición, a menos que entre los padres y los hijos exista un eslabón conexivo de alguna clase, tocante a algún asunto u otro; y he aquí, ¿cuál es ese asunto? Es el bautismo de los muertos. Pues sin ellos nosotros no podemos perfeccionarnos, ni ellos pueden perfeccionarse sin nosotros. $\mathrm{Ni}$ tampoco podemos nosotros $\mathrm{ni}$

131 Hen, 91-93. Cfr. F. García Martínez, «Apocalypticism in the Dead Sea Scrolls», en B. Mc Guinn, J.J. Collins \& S.J. Stein (eds.), The Continuum History of Apocalypticism, New York, Continuum, 2003, pp. 9697. Toda la escenografía del final del libro 1 de Henoc resulta bastante abigarrada y confusa, pues mientras que en el Libro de las visiones (90, 28-30) y en el Apocalipsis de las semanas (93, 3-10) el destino es la Nueva Jerusalén, terrestre, en el Libro de las enseñanzas y los castigos $(104,2-6)$ el estado de felicidad eterna para los justos acontecerá en el cielo.

${ }^{14}$ La biografía crítica «canónica» de Smith es No Man Knows My History, de F.M. Brodie (New York, Vintage, $2^{\mathrm{a}}$ ed. 1973). Aunque las visiones de Smith comenzaron muy pronto -supuestamente a los catorce años con la aparición de Dios Padre y de Dios Hijo- y le acompañaron toda su vida, fueron singularmente numerosas entre 1831 y 1836. Las escatológicas referentes al Juicio Final y al Reino Celestial tuvieron lugar en 1833, (cfr. Brodie, op. cit. p. 117 y ss.). Para los orígenes de la iglesia mormona pueden consultarse D.J. Davies, An Introduction to Mormonism, Cambridge U.P., 2003, y R. Stark, The Rise of Mormonism, Nueva York, Columbia U.P., 2005. 
ellos perfeccionarnos sin los que han fallecido en el evangelio; porque al iniciarse la dispensación del cumplimiento de los tiempos, dispensación que ya está comenzando, es menester que una unión entera, completa y perfecta, así como un encadenamiento de dispensaciones, llaves, poderes y glorias se realicen y sean revelados desde los días de Adán hasta el tiempo presente. Y no sólo esto, sino que las cosas que jamás se han revelado desde la fundación del mundo, antes bien fueron escondidas de los sabios y entendidos, serán reveladas a los niños pequeños y a los de pecho en ésta, la dispensación del cumplimiento de los tiempos ${ }^{15}$.

Smith combina hábilmente la inminencia y el carácter revelatorio incomparable y definitivo de la profecía milenarista con un cierto tinte mesiánico: el bautismo de los muertos (su mayor aportación teológica) que otorga salvación a ellos y perfeccionamiento a nosotros. Los acontecimientos que desencadenan el final de los tiempos ya han comenzado. Estamos, por así decir, en la prórroga, a las puertas del Armagedón.

Pasemos a un último ejemplo de este tipo, el de Mrs. Keech y las profecías extraterrestres $^{16}$. La historia, resumida a sus aspectos esenciales, es como sigue. Estamos a finales de los cuarenta, en California, donde surge el grupo de los indagadores (seekers). Los horrores de la II Guerra Mundial se hallan aún muy presentes y, sobre todo, la amenaza del enfrentamiento nuclear, así como la obsesión por los platillos volantes. Dorothy Martin (Mrs. Keech) recibe sucesivos mensajes de seres superiores mediante trances de escritura inconsciente inspirada. Le habla el Guardián, llamado Hermano Mayor, y en ocasiones un tal Samanda, que pretende haber sido el Jesús histórico. Se anuncia el comienzo de una Nueva Era (New Age) de luz en la que, al igual que Jesús derrotó al Príncipe de las Tinieblas, los Guardianes quieren despertar al mundo, en el único planeta en que campean todavía la guerra y el odio. Dorothy ha sido elegida por sus aptitudes espirituales para dar testimonio de la verdad y ser mediadora de la llegada de la luz ${ }^{17}$. Ulteriormente se informa de que, para atestiguar la verdad del mensaje, numerosos platillos volantes procedentes de Venus aterrizarán en las ciudades principales de la Tierra. Meses después se advierte que un gran diluvio anegará la Tierra en breve, destruyendo la mayor parte de EE.UU ${ }^{18}$ y Europa, pero los platillos llegarán a tiempo para rescatarla a ella y a sus fieles. La debacle se fecha para el 21 de diciembre de 1955. Llegado el momento nada acontece, y los fieles caen en el desconcierto, la incertidumbre y la ansiedad; algunos (pocos) en la desesperación.

\footnotetext{
15 Doctrina y convenios, 138, 18.

${ }^{16}$ El estudio clásico sobre Mrs. Keech y su grupo, que recopila los datos, es el libro de L. Festinger, H.W. Reicken y S. Schachter, When Prophecy Fails. A Social and Psychological Study of a Modern Group that Predicted the Destruction of the World, Univ. of Minnesota Press, 1956. Un resumen de la historia puede verse en J.S. Stone (ed.), Expecting Armageddon. Essential Readings in Failed Prophecy, New York, Routledge, 2000 (introducción, p. 6 y ss).

${ }^{17}$ Repárese en su doble papel de profeta (se le revelan los acontecimientos futuros) y mesías (propicia la llegada de la Nueva Era).

${ }^{18}$ Esto es bastante original, pues casi todos los milenaristas -al menos en las tradiciones del Libro- concuerdan en que el final acaecerá mediante el fuego, pues el recurso al agua ya fue empleado en el diluvio.
} 
Varios meses después Mrs. Keech recibe una nueva revelación del Hermano Mayor, felicitándolos calurosamente por la perseverancia en su fe y la valentía de su testimonio, que es lo que en realidad ha salvado en el último momento al mundo de una destrucción cierta. El llamado «Mensaje de Navidad a los Pueblos de la Tierra» reza: «Nunca jamás desde el principio de los tiempos ha existido en la Tierra tal energía de bien y de luz como inunda ahora esta estancia y que desde aquí liberada fluye sobre la Tierra entera».

En el ínterin, estudiantes del equipo de Festinger ${ }^{19}$ se han infiltrado en el grupo para estudiar las reacciones ante el fallo de la profecía. Nacerá la teoría de la disonancia cognitiva. La reacción mayoritaria del grupo es reafirmar la fe, lanzarse a un apostolado mucho más agresivo, y difundir por doquier y por todos los medios su nuevo evangelio. Así, se publica en la prensa local que «Gracias a la fe infinita de un pequeño grupo que pasó toda la noche rezando al raso, Dios salva al mundo de la destrucción final». Parafraseando a Churchill, podemos decir que ahora sí que «nunca antes tantos debieron tanto a tan pocos».

El caso de Mrs. Keech se ajusta cabalmente a la pauta del profeta escatológico: la humanidad ha degenerado por completo; se le anuncia -al profeta- el cataclismo que castigará a la humanidad; los que crean y se arrepientan se salvarán; el evento es inminente; la misión es dar la alarma general y tratar de salvar a cuantos se pueda. Al llegar el tiempo fijado y no ocurrir lo prometido, la sensación en el grupo es de aturdimiento y confusión. La reacción subsiguiente la analizaremos más adelante.

\subsection{DESCIFRAMIENTO-EXEGETA}

Las profecías de William Miller y del posterior movimiento adventista son un ejemplo paradigmático, como lo son las de los testigos de Jehová y las de varios movimientos cabalísticos. Todos incluyen fechas concretas.

Comenzamos con la historia del reverendo William Miller ${ }^{20}$. Nacido en Massachusetts, William Miller Biblia (1782-1849) desarrolló toda su actividad en Nueva Inglaterra, fue primero baptista, luego deísta y más tarde masón, llegando a Gran Maestro. En 1816 se convierte de nuevo al baptismo. Se hace pastor y se dedica al estudio intensivo de la Biblia, inicialmente para mostrar su compatibilidad con el deísmo. En 1818 descubre que la profecía concreta de la fecha del fin de los tiempos se halla oculta, principalmente en Daniel ${ }^{21}$. Miller interpreta la «Limpieza» como la purificación

\footnotetext{
${ }^{19}$ Los protocolos de actuación de los investigadores pueden verse en los apéndices del citado When Prophecy Fails.

${ }^{20}$ Para contextualizar el movimiento de Miller dentro de los movimientos milenaristas específicamente norteamericanos de los siglos XIX y XX, cfr. D. Dashke, «Millennial Destiny: A History of Millenialism in America», en E. V. Gallaher y W.M. Ashcraft (eds.), Introduction to New and Alternative Religions in America, Westport, Greenwood Press, 2006, Vol. I, p. 275 y ss. Y también S.J. Stein, «Apocalypticism Outside the Mainstream in the United States», en la citada Continuum History of Apocalypticism, p. 499 y ss.

21 [pregunta un santo a otro] «¿Hasta cuándo va a durar esta visión de la supresión del sacrificio perpetuo, de la asoladora prevaricación y de la profanación del santuario? Entonces dijo: hasta dos mil trescientas tardes y mañanas. Luego será purificado el Gran Santuario» (Dan 8, 14).
} 
mediante el fuego en la segunda venida de Cristo; cuenta los días bíblicos por años; tras denodados esfuerzos fija en 457 a C. el momento de la profecía de Daniel (esto era lo más difícil), desde el que empiezan a contar los 2.300 años. Si es correcto, el final será en 1843. Quedan justo 25 años para dar la alarma general.

Miller revisa y revisa, sin difundir nada hasta estar seguro. En agosto de 1831 comienza frenéticamente a predicar desde Vermont y a publicar en prensa. Abrumado por las cartas que le piden aclaraciones, concreción de la fecha, y las invitaciones a predicar en otros lugares, por fin publica en 1834: Evidence from Scripture and History of the Second Coming of Christ, about the Year $1843^{22}$. El movimiento se lanza a nivel nacional cuando partir de 1840 Joshua Vaugham Himes, reconocido pastor de Boston y director del periódico Signs of the Times, difunde la noticia. La ansiedad de los seguidores y los requerimientos se refieren sobre todo a que Miller determine de una vez la fecha exacta. A pesar de ello, Miller insiste en que no es capaz de reducir el «margen de error», pues hay una ambigüedad entre si debe emplearse el calendario judío o el gregoriano, lo que produce una diferencia de un año: «En resumen, mis principios son: que Jesucristo volverá de nuevo a esta Tierra, limpiará, purificará y tomará posesión de la misma, junto con todos los santos, en algún momento entre el 21 de marzo de 1843 y el 21 de marzo de $1844 »^{23}$. Se calcula que Miller y sus seguidores pudieron llegar a predicar en directo ante más de un millón de personas, de entre los cuales convencieron probablemente a unos cien mil (los cálculos de conversiones por los investigadores oscilan entre cincuenta mil y medio millón). A pesar de la precaución de Miller, muchos pastores seguidores suyos y sus fieles dieron por bueno sin más el 21 de marzo de 1843.

Está documentado que desde dos años antes los bancos cancelaron deudas, los campos se fueron dejando sin cultivar, y luego las cosechas sin recoger, se abandonaron haciendas, etc. a medida que se aproximaba la fecha ${ }^{24}$. El día de marras supuso una enorme decepción para decenas de miles de fieles, pero Miller advirtió que la fecha límite era el 21 de marzo del año siguiente. La mayoría siguieron fieles a Miller, sin embargo otros desertaron. Nada ocurrió tampoco en marzo del 44. Entonces Miller rehízo sus cálculos, esta vez según el calendario karaíta judío (frente al estándar rabbanita). Salía el 18 de abril del 44. Tampoco pasó lo previsto. Los fieles fueron

\footnotetext{
${ }^{22}$ Ahí se lanza la campaña de difusión generalizada de la alarma: «Una vez más, permíteme indagar qué pasa contigo, mi querido oyente: ¿estás preparado para ese gran y solemne día? ¿Estás listo para afrontar el Juicio?»; edición moderna de la obra en BiblioBazaar, 2009, p. 202.

${ }^{23}$ Citado en N. Dick Everett, William Miller and the Advent Crisis, Berrien Springs, Andrews University Press, 1994, pp. 96-97 (cursivas mías). Esta es una de las pocas monografías dedicadas a los milleritas, pero está sesgada por la militancia adventista de su autor.

${ }^{24}$ El cese de actividades por inminencia del fin de los tiempos se remonta muy atrás en la historia del milenarismo. A comienzos del siglo II a. C., entre los judíos, los esenios abandonaron sus quehaceres y se refugiaron en las cuevas del Mar Muerto a la espera del fin del mundo, viviendo con lo mínimo imprescindible (Cfr. F. García Martínez - J. Trebolle Barrera, Los hombres de Qumrán, Madrid: Trotta, 2a ed. 1997, esp. parte I «Los hombres de la comunidad de Qumrán»). Y hacia los años sesenta del mismo siglo, varias comunidades cristianas de Tesalónica habían dejado de trabajar y se habían sentado a esperar la segunda venida, como refleja el autor de 2 Tes 3, 10 .
} 
abandonando a Miller progresivamente. Miller se rindió a la evidencia: «Confieso mi error, y reconozco mi desilusión; no obstante, aún creo que el día del Señor está próximo, incluso a las puertas» ${ }^{25}$.

El caso de Miller ilustra muy bien el tipo de profeta hermeneuta. No tiene poderes especiales, ni recibe revelación alguna desde las alturas. No pretende fundar una religión, ni modificar una existente. Se sitúa dentro de una religión ya establecida, acepta sus sagradas escrituras, y dedica su vida a descifrar el mensaje oculto en ellas acerca del final de los tiempos o, más concretamente, acerca de cuándo advendrá, dado que el cómo ya está manifiesto en los libros correspondientes (en su caso, Isaías, Daniel y el Apocalipsis).

El fracaso de la profecía también es ilustrativo. Miller es un estudioso, un erudito. Su fallo es un «error de cálculo»: ha errado en la fecha, pero las creencias de su religión quedan intactas, incluidas las referentes a que habrá un fin sobrenatural de los tiempos y cómo acontecerá. Naturalmente, para los milleritas el fallo, además reiterado, supone su hundimiento; pero la religión cristiana como tal sale intacta. En cambio, un fallo clamoroso de un profeta escatológico supondría que su revelación había sido espuria, y por ende falsas las creencias derivadas de ella. En otras palabras, supondría tener que reconocer que era un falso profeta ${ }^{26}$. Pero el profeta apocalíptico escatológico nunca da fechas concretas; proclama en todo caso la inminencia de los sucesos, pero el concepto de inminencia es lo suficientemente vago como para permitir evitar una refutación pura y dura ${ }^{27}$.

Y bien, ¿qué ocurrió con los milleritas y su reacción ante el estrepitoso fracaso? El fallo de la profecía y la reinterpretación adventista del gran chasco ilustra una reacción que, si no es universal -ni siempre se reacciona así ni todos los milleritas lo hicieron por igual- sí es bastante frecuente: reinterpretar la profecía, de lo cual resulta que ésta en realidad sí se ha cumplido, y añadir una nueva profecía -o prolongar hacia el futuro la manifestación particular de esa profecía que dibuja el texto sagrado (p.ej. el Apocalipsis) y dio por buena el exegeta (Miller, en este caso). Veamos lo que sucedió con los Adventistas del Séptimo Día.

\footnotetext{
${ }^{25}$ Sylvester Bliss, Memoirs of William Miller, Boston, Joshua V. Himes, 1853, p. 256.

${ }^{26}$ Es interesante el caso de Joseph Smith. Sus detractores lo acusaban continuamente de «falso profeta» -que era la acusación más odiada por él-. En una ocasión, cuando necesitaba fondos para publicar su recién acabado Libro Mormón, envió en misión a dos de sus más allegados -Oliver Cowdery e Hiram Page-, a Toronto para recaudar fondos, porque había tenido la revelación de que allí los apoyaría un gran potentado. Tras el fracaso absoluto y la consiguiente perplejidad de sus enviados declaró que: «Algunas revelaciones proceden de Dios, algunas del hombre, y algunas del demonio... Cuando un hombre inquiere al Señor sobre un asunto, si es engañado por sus propios deseos carnales, y se halla en error, recibirá una respuesta conforme a su corazón errado, pero no será una revelación del Señor» (La historia es referida por David Whitmer en Address to All Believers in Christ. Cfr. F. M. Brodie, op. cit, p. 81).

27 Pablo afirma $(1$ Cor 15,51$)$ que no todos moriremos y que al son de la trompeta resucitarán los muertos. Aunque por el contexto se refiere a sus coetáneos (en consonancia con la más explícita 1 Tes 4, 17), y con ello proclama una relativa inminencia, puede forzadamente reinterpretarse en el sentido de que el final, advenga cuando sea, pillará vivos a varios. Por el contrario, el autor de la Segunda carta a los Tesalonicenses, posterior a Pablo y que ya está experimentando el retraso, afirma: «no os alarméis ni por espíritu, ni por discurso, ni por epístola aun si fuera nuestra, como si el día del Señor fuera inminente» (2, 2; cursivas mías).
} 
Los últimos cálculos expuestos en una reunión pública en Vermont, ya no por un desengañado Miller, sino por Samuel Snow, fijaban el 22 de octubre del 44 como última fecha posible. Ese día pasó a ser conocido por los milleritas adventistas como El Gran Chasco. Una millerita, Ellen Gould White (1827-1915), comienza a tener visiones en ese año de 1844. En una de ellas se le anuncia ${ }^{28}$ que Miller en el fondo estaba en lo cierto, y que la profecía se ha cumplido «en el Cielo», porque la «limpieza del Santuario» significa la entrada de Jesús en el lugar más santo del Santuario Celeste, y la preparación del Cielo para acoger a todos los resucitados. Esto es lo que efectivamente comenzó en marzo del 44, y que inicia el llamado «juicio inquisitivo» (Dios examina a todos para ver quiénes merecen ser admitidos al cielo). Cuando el juicio termine y el cielo esté listo, advendrá el fin de los tiempos, que en todo caso sigue estando próximo. Siguiendo al Apocalipsis -Ellen no se interesa especialmente por Daniel- la segunda venida será manifiesta y precedida por el Anticristo. Otros milleritas afirman haber tenido revelaciones coincidentes con las de Ellen, incluso antes que ella y antes del Gran Chasco. Ellen Gould tiene muchas revelaciones ulteriores, que la llevan a fundar la Iglesia Adventista del Séptimo día (16 millones de fieles actualmente).

A medida que pasan los años y no adviene el final tal y como lo describe el Apocalipsis, la doctrina del «juicio inquisitivo» se debate, se reinterpreta, se sutiliza o se abandona, siendo origen de innumerables polémicas dentro de los adventistas hasta la actualidad. Algo parecido ocurre con la interpretación de la «Limpieza del Santuario». Las profecías escatológicas pasan a un segundo plano, y la inminencia de la segunda venida se entiende de modo más y más laxo. Como señalé arriba, es extremadamente raro que a un profeta apocalíptico escatológico le sean reveladas fechas exactas, con lo que determinar el fracaso de la profecía es mucho más problemático. Son los descifradores o hermeneutas los que se arriesgan con fechas. El caso paradigmático y recalcitrante en la historia de las religiones son los Testigos de Jehová.

El pastor restauracionista Charles Taze Russell (1852-1916) organiza en Pittsburgh en los años ochenta del siglo XIX el Movimiento de Estudio Bíblico, funda en 1879 la revista Zion's Watch Tower and Herald of Christ's Presence, y en 1881 co-funda la Zion's Watch Tower Tract Society. Entre 1886 y 1904 escribe y publica The Millenial Dawn, y en 1908 instala su cuartel general en Brooklyn, Nueva York (donde sigue en la actualidad). Según su doctrina, Cristo ha vuelto (invisiblemente) en 1874, para preparar el final de los tiempos. Charles predice el Armagedón para $1914^{29}$. Al fallar la pro-

\footnotetext{
${ }^{28}$ Es decir, tiene revelaciones, lo que la convierte en profeta apocalíptica escatológica. Ellen no es ninguna estudiosa ni cabalista: no descifra mensajes ocultos, se atiene a lo que se le desvela explícitamente desde las alturas. Como introducción al movimiento fundado por Ellen, la Iglesia Adventista del Séptimo Día, cfr. D. Morgan, «The Adventist Tradition», en Introduction to New and Alternative Religions in America (Vol. II, pp. 38-61). El estudio clásico sobre la fundadora del movimiento es R. Graham: Ellen G. White. Co-Founder of the Seventh-day Adventist Church, Nueva York, Peter Lang, 1985. Para el surgimiento del movimiento adventista a partir del millerita, Cfr. I. Lindén: The Last Trump. An Historico-Genetical Study of Some Important Chapters in the Making and Development of the Seventh-day Adventist Church, Frankfurt del Meno, Lang, 1978.

${ }^{29}$ En 1876 en Filadelfia Nelson Barbour había convencido a Russell de que 1878 sería el año del rapto paulino. Russell predicó activamente el final de los tiempos, pero ante el fallo se desentendió del pronóstico,
} 
fecía, rehacen sus cálculos (primero él y luego sus seguidores) una y otra vez, hasta cinco veces, fallando la última en 1925. El grupo sufre entonces varias escisiones y abandonos. Uno de los grupos resultantes se bautiza como Testigos de Jehováa ${ }^{30}$. Se incrementa mucho en los sesenta, y vuelve a profetizar con vehemencia el Armagedón para 1975. Tras el fallo, no vuelve a haber pronunciamientos sobre fechas concretas.

Charles Russell es un exegeta hermenéutico. A diferencia de Ellen White, no tiene visiones ni recibe mensajes sobrenaturales. Es un estudioso que mezcla sus conocimientos bíblicos - la Biblia, en su versión particular, se considera infalible- y su intelección personal de los acontecimientos históricos. Se arriesga y pierde. El fracaso clamoroso dinamita el grupo original. De entre los residuales, surgen los Testigos de Jehová, que vuelven a arriesgarse con una fecha concreta. Pero al primer nuevo fallo aprenden la lección: no más fechas. El Armagedón es inminente, pero la inminencia se reinterpreta: posiblemente acaecerá sólo cuando los Testigos de Jehová -obviamente representantes de la única religión verdadera y por tanto con poder salvíficohayan predicado su evangelio por toda la Tierra ${ }^{31}$.

\subsection{CUMPLIMIENTO-MESÍAS}

La llegada del mesías y con ella el cumplimiento del tiempo ha sido tema central de la tradición judeo-cristiana. Jesús de Nazaret es anunciado como tal por Juan Bautista. El mismo Jesús predice su segunda y definitiva venida como muy próxima. Un caso célebre dentro del judaísmo es la historia de Sabbatai-Sevi ${ }^{32}$. Como el caso de Jesús de Nazaret es de sobra conocido, me centraré en el de Sabbatai.

lo consideró una malinterpretación de los textos bíblicos, y rompió con Barbour (cfr. J.B. Parkinson, The Bible Student Movement in the Days of CT Russell, Los Ángeles, publicado por el autor, 1965, p. 2-3 [disponible en http://www.globallight.org.uk/downloads/Vertical\%20Lines.pdf]).

${ }^{30}$ La bibliografía sobre este movimiento es amplia. Cfr. D.L. Weddle, «Jehovah’s Witnesses», en Introduction to New and Alternative Religions in America (op. cit. Vol. II, pp. 62-88). Para los aspectos filosóficos y sociológicos, véase J.F. Zygmunt, «Prophetic Failure and Chiliastic Identity» y N.M. Schmalz: «When Festinger Fails. Prophecy and the Watchtower», ambos en Expecting Armageddon, pp. 65-86 y 233-250.

${ }^{31}$ Alguien podría pensar que con Internet, dada su difusión mundial, la inminencia es definitiva, y que no podrá postergarse más. Pero los Testigos insisten en que el verdadero evangelio ha de ser predicado «puerta a puerta»: porque fue una tarea encomendada por Jesucristo y emprendida por los primeros apóstoles, y porque sirve para que todos y cada uno tengamos la posibilidad efectiva -no meramente teórica- de aceptar el Evangelio y la responsabilidad individual en caso de rechazarlo. Cfr. «House-to-house Ministry», en G.D. Chryssides, Historical Dictionary of Jehovah's Witnesses, Lanham, Scarecrow Press, 2008, p. 75.

${ }^{32}$ La historia de Sabbatai deja en pañales a cualquier película de aventuras. El estudio más completo es el de G. Scholem, Sabbatai Sevi. The Mystical Messiah, Princeton Uni. Press, 1973. Más manejable es Die jüdische Mystik in ihren Hauptströmungen, Frankfurt, Suhrkamp, 1951 (trad. esp. Las grandes tendencias de la mística judia, Madrid, Siruela, 1996; cfr. el capítulo 8: «El sabbateanismo y la herejía mística»). Mircea Eliade, empero, despacha el movimiento en dos páginas, y afirma: «En cuanto al mismo Sabbatai, no escribió nada ni se le atribuye mensaje alguno original o palabra digna de recordarse» (Historia de las creencias y de las ideas religiosas, Vol. III, Madrid, Cristiandad, 1983, p. 186). Lo incómodo del episodio de Sabbatai para los judíos se muestra en que la monumental Encyclopedia Judaica (Nueva York, Macmillan, $2^{\mathrm{a}}$ ed. 2006) ni siquiera le dedica uno de sus 22.000 artículos. 
Como es natural, profetas ha habido muchos; descifradores bastantes, pero mesías muy pocos, porque un mesías supone normalmente el cumplimiento de varias profecías de numerosos profetas dentro de su tradición. Si un mesías pasa a la historia como genuino, entonces o acaba con la historia -lo cual aún no ha sucedido- $\mathrm{u}$ origina -incluso sin proponérselo- una nueva religión. Como lo primero nunca ha ocurrido, sus inicialmente prosélitos tenderán a considerarlo un falso mesías. Pero si acontece lo segundo, algunos se pasarán de la religión antigua a la nueva. Dependiendo del éxito, los historiadores considerarán a la nueva como una religión -como ocurrió con el cristianismo- o como una secta -como ocurrió con los sabbatianos, que al parecer siguen existiendo aunque muy reducidos en número en la Turquía actual-. Naturalmente los fieles a la religión original siguen esperando a su mesías. Así ocurre con los judíos, y también con los musulmanes. Veamos el ejemplo de Sabbatai con cierto detalle, porque es tremendamente representativo.

El Zohar, según una interpretación, predice el advenimiento del Mesías para 1648. Diversos movimientos milenaristas en Europa -inicialmente sobre todo cristianos, pero más adelante también judíos-, particularmente en los Países Bajos y en Gran Bretaña, esperan el advenimiento final del Mesías en algún momento de la segunda mitad del siglo XVII; uno de los grupos más influyentes lo acaba concretando para $1666^{33}$, según cálculos basados en el Apocalipsis ${ }^{34}$. Varias comunidades de misioneros mile-

${ }^{33}$ El hiperactivo comerciante holandés y heterodoxo teólogo calvinista Peter Serrarius, junto con los rabinos de Ámsterdam, alentados por el rabino de Jerusalén Nathán Shapira - de visita en Ámsterdam dentro de una gira europea para recaudar fondos- llegaron en 1664 a la conclusión de que el Mesías advendría en 1666. Los milenaristas más comprometidos de Gran Bretaña eran amigos de Serrarius y estaban al día de tales cábalas y de los (supuestamente milagrosos) acontecimientos que constituian signos inequívocos del advenimiento. Cuando en 1666 la Sinagoga de Ámsterdam recibe una carta de Sabbatai anunciando el comienzo de la era mesiánica, Serrarius envía inmediatamente una copia a su amigo el teólogo escocés, residente por entonces en Suiza, John Dury. El suegro de Dury, Henry Oldenburg - primer secretario de la Royal Society- escribe con tal ocasión a su amigo Spinoza para que le informe de qué es lo que verdaderamente está ocurriendo en Constantinopla. Naturalmente, también están al tanto de todo los demás miembros de la Royal Society, empezando por Robert Boyle, así como los milenaristas del influyente círculo de Samuel Hartlib (cfr. R.H. Popkin, «Christian Interests and Concerns about Sabbatai Zevi», en M.D. Goldish \& R.H. Popkin (eds.), Jewish Messianism in the Early Modern World, Dordrecht, Kluwer, 2010, p. 91s.). Como los milenaristas cristianos lo que esperaban con ansiedad era la conversión de los judíos, la reunificación de las iglesias (o, en el caso de los protestantes, el triunfo de la Iglesia Luterana -o Reformada, o Anglicana, según el caso- sobre la corrupta y demonizada Iglesia Romana) y, por encima de todo, la segunda y triunfante venida de Jesús, la aparición de un mesías genuino de entre los judíos era realmente turbadora: ¿entonces Jesús había sido un falso mesías? ¿Tal vez Sabbatai era la reencarnación del mismo Jesús? ¿O acaso Dios se había reconciliado con los judíos y les enviaba a su propio mesías antes del millenium? Todo esto rompía los esquemas a cristianos milenaristas como John Dury o Jean de Labadie, y generó un acalorado debate hermenéutico (cfr. Popkin p. 93s.).

${ }^{34}$ Quien mejor argumentó en Gran Bretaña que los signos de los tiempos presentes coincidían con los anticipados en el Apocalipsis fue Joseph Mede (1586-1638). A pesar de no predicar públicamente sus ideas fuera del ámbito académico ni realizar apostolado activo alguno, tuvo mucha influencia a través de sus notables discípulos en Cambridge, y era considerado la máxima autoridad en el Apocalipsis por muchos cristianos ilustrados, como Henry More, Robert Boyle o Isaac Newton. Su Clavis apocalyptica (1627, traducida al inglés en 1643), que indicaba 1654 como una posible fecha del fin del mundo, alcanzó mucha repercusión, así como posteriormente la edición póstuma completa de sus obras por John Worthington (en 1664) tuvo gran influencia en la convulsa escena religiosa y política de la época (cfr. S. Hutton, «The Appropriation of Joseph Mede: Millenarianism in the 1640 s», en J.E. Force \& R.H. Popkin [eds.], op. cit. pp. 1-15). 
naristas, p.ej. de cuáqueros, residen y difunden sus ideas en Constantinopla, Esmirna y Jerusalén en la década de 1650. Sabbatai Sevi (1626-1676), fue un rabino experto en la cábala que sufría alteraciones radicales en su estado de ánimo y tenía frecuentes accesos de furor religioso. Desde 1648 predicó activamente por Oriente Medio la proximidad del final de los tiempos, a la par que iba sospechando - pero difundiendo sólo entre los allegados- que acaso él mismo fuera el Mesías. Tras unos quince años de activo apostolado y notable éxito, en 1665 una autoridad religiosa reconocida ${ }^{35}$, el también cabalista Natán de Gaza, al conocerlo, le persuade de que, sin duda, él es el verdadero Mesías, y que el inicio de su reinado es inminente. Con tales credenciales una muchedumbre en Esmirna proclama a Sabbatai Mesías, y él se presenta como tal ya públicamente. La noticia se extiende como la pólvora por las comunidades judías de la diáspora que ya estaban a la expectativa, desencadenando el entusiasmo desde Holanda hasta Yemen, desde Marruecos hasta Persia ${ }^{36}$. También afecta decisivamente a los protestantes milenaristas. En Gran Bretaña y en otros países protestantes europeos abundan los rumores: ...que si las diez tribus perdidas de Israel avanzan por el norte de África, ...que si su vanguardia acaba de capturar la Meca, ...o que parte de las tribus venidas del Norte han atracado en el puerto escocés de Aberdeen, en ruta hacia Levante. Decenas de panfletos propalan los rumores como si fueran noticias. Tanto en la Royal Society ${ }^{37}$ como en el gobierno británico quieren saber qué hay de verdad en todo esto.

Pero si la historia de tales eventos en Europa es apasionante, aún lo es más en el Oriente Medio. Con sorprendente indolencia por parte de las autoridades otomanas, el Rey-Mesías Sabbatai comienza a recibir en Esmirna embajadas de los judíos de todo el mundo y va nombrando reyes-delegados que regirán subsiguientemente las naciones a modo de vasallos. El nombre de Sabbatai reemplaza al del sultán en las oraciones públicas en las sinagogas. Sabbatai inaugura la Nueva Era: inicia el cómputo del tiempo $(1666$ = año 1), cambia el calendario, altera las fiestas judías, modifica la Torah, etc. El sentimiento de jubileo reemplaza al de sufrimiento. Seis meses después Sabbatai se dirige a Constantinopla a convencer al sultán de que se rinda ante el Mesías, y convierta el Imperio Otomano al judaísmo. Así, en la primera fase, la conversión de las

\footnotetext{
35 Es común este patrón según el cual el profeta mesiánico no se revela como tal ni triunfa públicamente hasta que una autoridad religiosa «oficial» y reconocida, a menudo con un cargo institucional -y casi siempre sin poderes carismáticos sobrenaturales- lo reconoce y autentifica como tal. Lo hemos visto con Miller y Vaugham Himes, y se dio en buena medida con Jesús y Juan Bautista.

${ }^{36}$ Algunos historiadores del judaísmo estiman que hasta un 90\% de los judíos de la época creyeron en el mesianismo de Sabbatai, pero es muy difícil verificar tales cifras. Además, «creer en» es tremendamente vago y admite mucha graduación. Sí es posible que una cifra semejante de judíos al menos tomara en consideración las noticias sobre Sabbatai y les diera mayor o menor credibilidad. Lo constatado es que generó muchísima expectación y ansiedad, y no solamente entre los judíos.

${ }^{37}$ No debe sorprender la credibilidad que muchos científicos británicos de la época concedían a las profecías milenaristas, e incluso que algunos ejercieran de exegetas descifradores de fechas. Al igual que muchos teólogos consideraban que los prodigios de la nueva ciencia experimental eran un signo del cumplimiento de los tiempos, muchos filósofos naturales eran cristianos convencidos, incluidas las creencias escatológicas, variando el tipo de milenarismo de unos a otros (cfr. notas 9 y 33).
} 
naciones al judaísmo procederá sin derramamiento de sangre ${ }^{38}$. Una vez conquistado el Oriente, habrá que proceder hacia Occidente, presumiblemente esta vez con el uso de la fuerza. Será entonces cuando el Mesías ejerza de caudillo militar. Para persuadirlo, Sabbatai prometerá al sultán dejarle ocupar el cargo de Gran Visir suyo de todo el imperio otomano-judío, mientras dure la conquista del resto del mundo.

En septiembre de 1666, y antes de poder acceder al sultán, el Gran Visir-que era quien ejercía de facto el poder ejecutivo- lo encarcela, pero en una prisión de lujo. Ante la indecisión del sultán, en abril lo trasladan a Gallipolli a otra estancia aún más lujosa (en una especie de arresto domiciliario) donde se le permite ejercer funciones de la corte, como si fuera el Mesías inminente. Finalmente en septiembre de 1667 lo devuelven a Constantinopla y, cuando todos sus fieles piensan que por fin el sultán ha cedido y se ha convertido, éste le hace una contraoferta irrechazable en forma de trilema: o realiza públicamente un milagro que demuestre inequívocamente su carácter mesiánico, o es ejecutado por impostor, o reconoce su impostura y salva la vida haciendo apostasía del judaísmo y convirtiéndose públicamente al Islam (al parecer Mohammed IV y los clérigos musulmanes de la corte pensaban que, si Sabbatai aceptaba, podría convertir en bloque a sus numerosos fieles, incluso quizá a todos los judíos, al Islam). Para estupor de muchos de sus seguidores, Sabbatai opta por la tercera alternativa. Eso significa para ellos que han de soportar la humillación, la vergüenza, el ridículo y el escarnio. P.ej. en Ámsterdam se confiscan sus libros de oración y se prohíbe pronunciar su nombre. Algo parecido ocurre en el resto de las comunidades judías de Europa. Quienes sigan siendo sabbateanos, deberán practicar su judaísmo en secreto.

Pero otros lo ven de modo muy distinto. Para Natán de Gaza la glorificación del redentor apóstata se ensalza como el más profundo y paradójico de los misterios. Las inconmensurables acciones de Sabbatai constituyen la prueba de autenticidad de su mesianismo. Lo fácil habría sido aceptar el martirio. Natán escribe, interpreta y articula el movimiento en una nueva secta/religión. Como hizo Pablo en su momento, Natán realizará una infatigable tarea de visitar congregaciones, pronunciar sermones y escribir cartas a las comunidades judías. El trágico destino de Sabbatai es interpretado en los términos de Cántico del Siervo de Isaías (53), como hubo ocurrido con Jesús. Según su discípulo Cardozo, sólo el alma del Mesías puede resistir el sacrificio de hundirse hasta el fondo del abismo (idea cuya inspiración se halla en el Zohar y en los escritos de Isaac Luria). Para cumplir su misión, el Mesías ha de condenarse a sí mismo. Llegados a este punto, los sabbateanos se escinden entre quienes piensan que el Mesías se ha sacrificado y condenado para salvar a los demás, y quienes añaden que representa un modelo a seguir: todos debemos descender a los infiernos y combatir el mal con el mal ${ }^{39}$.

${ }^{38}$ Esto es una gran novedad, el que haya una primera fase pacífica, incruenta, en la transición de la historia al millenium.

${ }^{39}$ La cosa no acaba aquí. Un siglo después, el sabbateano Jacob Frank en la Polonia oriental (actual Ucrania) afirma ser la reencarnación de David y de Sabbatai. Funda un nuevo movimiento religioso judío que acepta el Nuevo Testamento, la Ilustración y la doctrina sabbateana de la «purificación mediante la transgresión» 
El caso de Sabbatai es extraordinariamente interesante desde el punto de vista fenomenológico. Es un erudito, un cabalista, y por ende un exegeta y hermeneuta, aunque son otros - como Serrarius, los rabinos de Ámsterdam o los cuáqueros- quienes han dictaminado 1666 como el año del final de la historia. Pero asimismo tiene visiones y revelaciones, incluidas sobre el porvenir, como los profetas apocalípticos escatológicos. Él mismo duda de su identidad. Pero finalmente es otro quien le acaba por convencer de que efectivamente es el Mesías. En suma, se trata de un exegeta, devenido profeta y que acaba revelándose como mesías, un verdadero todo-en-uno en la tipología milenarista.

Es menester reparar en esto: si la fecha del final ya está dictaminada -por quien fuere-, aceptada como válida y está muy próxima, las revelaciones escatológicas de Sabbatai no pueden ser las del profeta de una religión del porvenir, a largo plazo, sino de los últimos días. De ahí la duda sobre si él es el heraldo de la consumación de los tiempos que está a punto de protagonizar el Mesías o es el Mesías mismo.

\section{REACCIONES ALTERNATIVAS ANTE EL INCUMPLIMIENTO PROFÉTICO}

Hasta ahora todas estas profecías han fallado, lo cual no ha desanimado mucho a los sucesivos profetas. Más aún, si los siglos XVIII y XIX fueron prolíficos en sectas milenaristas -muy especialmente en Norteamérica- el siglo XX ha visto crecer exponencialmente el número y diversidad de profecías milenaristas, así como su transmutación secular ${ }^{40}$ (los mil años pronosticados al Tercer Reich, por ejemplo.) Pero, ¿cómo se sobrevive al fracaso de la profecía?

El famoso estudio inicial de Festinger referido arriba indicaba una reacción casi unánime de los prosélitos: tras la desilusión inicial y la consiguiente desorientación, surge una actitud de reafirmación, que comporta el atrincheramiento, la hostilidad hacia el exterior, un apostolado más agresivo, etc. Y todo ello basado en el supuesto de que la profecía en ningún caso ha fracasado, sino que se ha malinterpretado. Sin embargo, los estudios posteriores muestran que las reacciones son bastante más diversas y divergentes. En primer lugar, que también hay quienes admiten el fracaso y abandonan el grupo y sus doctrinas, sea para repudiar del todo las ilusiones milenaristas, sea para entregarse a las especulaciones de otros grupos. En segundo lugar, entre quienes se quedan hay numerosas y acaloradas discusiones acerca de cómo reinterpretar los hechos para evitar tener que aceptar un fracaso de la profecía; y que tales polémi-

(que incluye las orgías sexuales). A pesar de la fuerte persecución por los judíos ortodoxos, para 1790, 26.000 seguidores de Frank han recibido el bautismo en Polonia. Frank es encarcelado, pero el movimiento se extiende a Hungría y Ucrania.

${ }^{40}$ Esto sucede de modo paradigmático en los EE.UU., donde han seguido proliferando las profecías sobre el inminente Armagedón, cuyos agentes propiciadores han ido cambiando a lo largo del siglo: la Alemania Nazi, invasores extraterrestres, la Unión Soviética, los países árabes, el Irán de Jomeini, el Irak de Sadam Hussein o Al Qaeda... (cfr. P. Boyer, When Time Shall Be No More. Prophecy Belief in Modern American Culture, Harvard, Belknap Press, 1994). 
cas provocan muy a menudo escisiones o cismas. En suma, que hay una importante diversidad en cuanto a los modos de gestionar el fracaso de la profecía.

Podemos establecer cuatro tipos de reacciones ante el putativo fallo del milenarismo profético. 1) La profecía sí se ha cumplido, pero a nivel espiritual, bien en la Tierra (Juan evangelista) o en el cielo (los adventistas y su «Limpieza del Santuario»). 2) Ni ha fallado ni se ha cumplido, lo que ha habido es un «error de cálculo» (esto es propio de las profecías tipo desciframiento-exegeta). Entonces o bien a) se revisan los cálculos y se reformula la fecha - que sigue siendo próxima- tras lo cual se vuelve al estado de alerta y espera activa (Miller, testigos de Jehová); o bien b) se remite a un futuro inconcreto (Mt24, 42); o bien c) tras rehacer los cálculos se remite a un futuro específico, pero muy distante (dentro de diez mil años, etc.). 3) Ni se ha cumplido ni se ha dejado de cumplir, porque la profecía tenía un carácter condicional: se anunciaba lo que iba a ocurrir «a menos que» reaccionáramos (recapacitáramos, nos convirtiéramos...), y hemos reaccionado a tiempo (Mrs. Keech y sus profecías sobre un segundo diluvio universal). 4) Se insiste en que tiene que estar a punto de cumplirse, según el modelo de la falacia del jugador del casino, y se redoblan los esfuerzos en proselitismo para aliviar la ansiedad.

¿Qué decir de la «rentabilidad» de cada una de estas reacciones alternativas? La cuarta da muy poco juego, pues enseguida termina por agotarse su recorrido, de modo que son las tres primeras las más viables y habituales. La tercera posee un potencial escaso, pues aparte de su carácter patente y sospechosamente ad hoc ${ }^{41}$, si ya hemos reaccionado positivamente, si ya nos hemos reconciliado con la divinidad, se desactiva el mensaje religioso de «es menester cambiar radicalmente de actitud, porque el (castigo) final es inminente». La segunda alternativa en su versión (a) acaba por agotarse más pronto que tarde, pues los fieles se desengañan definitivamente después de reiterados fracasos sucesivos, con lo que la profecía se acaba dando por refutada. Por el contrario, las versiones (b) y (c) tienen la gran ventaja, respectivamente, de ser irrefutable o de no ir a ser contrastada (y por tanto posiblemente refutada) hasta dentro de mucho tiempo. Aparte de esta indudable ventaja, la versión (c) es en cierto sentido menos «operativa» que (a), pues, aunque la «espada de Damocles» sigue pendiendo, al ser a muy largo plazo su potencial motivador disminuye: si sabemos que no vamos a ser testigos del final, no hay posible movilización general «por cierre de universo». La versión (b), en cambio, da mucho más juego, pues la profecía-amenaza sobre el final no sólo sigue en vigor, sino que sigue siendo en buena medida acuciante, dado que puede acaecer en cualquier momento y por ende, si no la movilización, al menos la alerta y la llamada al cumplimiento de las obligaciones religiosas y morales es permanente y perentoria. Es justamente esta ambigüedad en cuanto a la inminencia del final -y por tanto en cuanto al carácter milenarista de la profecía - lo que hace esta alternativa tan versátil y atractiva: compagina un cierto grado de movilización ante el final con la irrefutabilidad ante su demora ${ }^{42}$. Por último, la opción primera, la «espiritualización» de la profecía, re-

\footnotetext{
${ }^{41}$ El carácter condicional de la profecía suele revelarse post facto y raramente desde un principio, lo que convierte su supuesta condicionalidad en harto sospechosa.

${ }^{42} \mathrm{Al}$ principio distinguimos entre profecías milenaristas en sentido estricto, cuando lo inminente es la llagada del millenium, y en sentido laxo, cuando lo inminente es el eschaton-con millenium, sin él o con
} 
porta notables ventajas: 1) la profecía no sólo no ha fracasado, sino que se ha cumplido (lo cual corrobora la verdad de la religión y la veracidad de su profeta escatológico); 2) al haberse cumplido «en otra esfera de la realidad» su cumplimiento no es verificable (y por ello irrefutable); y 3) esta espiritualización de la profecía puede aportar significativas innovaciones teológicas. Sin embargo, también conlleva inconvenientes: 1) su no verificabilidad plantea serios interrogantes sobre su efectivo cumplimiento, lo hace sospechoso; 2) al haberse cumplido la profecía, desaparece la movilización (como en 2c). Claro que el suspender la «alerta general por inminencia del final de los tiempos» puede representar una ventaja para la supervivencia de una religión a largo plazo, pues no se puede estar permanentemente alerta y movilizado.

Por otra parte, no todos estos tipos de reacciones son mutuamente excluyentes. Así, p.ej. tras los primeros fracasos, los testigos de Jehová combinan el rehacer los cálculos de fechas con el aumento del proselitismo, mientras que el último fracaso -el de 1975- provoca una suspensión de la predicción concreta de una fecha y su remisión a un futuro cercano pero inespecífico ${ }^{43}$. Lo curioso es que, según los razonamientos anteriores, sería de esperar que los movimientos proféticos milenaristas acabaran todos pronto en el estado (1), (2b) o (2c), que son estables y están a salvo del fracaso, porque al eliminar la inminencia ( 1 y $2 c$ ) o dejarla como interrogante (2b) pierden o, en su caso, difuminan su carácter propiamente milenarista. Pero de hecho a menudo no ocurre así, o al menos no dejan de surgir sectas nuevas que siguen las otras alternativas de alto riesgo, las respuestas fieles al programa milenarista. El hecho es que, pese a los reiterados fallos al profetizar la fecha del fin del mundo ${ }^{44}$ estas predicciones se han seguido y se siguen produciendo una y otra vez. No hay duda del fuerte atractivo que tienen las creencias apocalíptico-escatológicas milenaristas sobre las mentalidades religiosas más o menos ingenuas y fanáticas, pero no deja de ser un enigma que, incluso en países desarrollados como EE.UU., y especialmente en él, tales creencias renazcan sin cesar y sigan gozando de una más que notable aceptación. Este es un tema apasionante tanto para la sociología como para la psicología de la religión.

una ambigüedad al respecto-. Pero esta opción (2b) añade un tercer tipo, que podríamos denominar $p s e u d o-$ milenaristas: cuando el eschaton es potencialmente inminente. El hecho de que el final pueda acaecer en cualquier momento hace que sea poco probable que vaya a ocurrir inmediatamente, pues el momento actual es plausiblemente uno cualquiera de los muchos de la historia, lo cual tiende a desactivar el componente político del milenarismo. Sin embargo, por otro lado, el mismo hecho de que sea posible que ocurra ya mismo hace que la perfección moral sea una exigencia sobre la que nunca jamás podemos bajar la guardia.

${ }^{43}$ Su obsesión por la cronología bíblica y su fe ciega en ella, aunque muy reacios ya a volver a fijar fechas, puede verse en C.F. Redeker, A Confirmation of the True Bible Chronology, Southfield, 1971, $5^{\mathrm{a}}$ ed. 2002 [disponible en http://www.biblestudents.net/studies/chronology/truechrn.pdf]. El atrevimiento de determinar la fecha del fin de los tiempos se ha sustituido por el estudio comparativo y el debate interminable sobre la cronología, infalible pero críptica, oculta en la Biblia.

${ }^{44}$ Puede verse una curiosa lista de medio centenar profecías fallidas desde Jesucristo hasta nuestros días en http://www.religioustolerance.org/end_wrl2.htm. La Universidad de Boston tiene un Center for Millenial Studies cuya página web inicial (http://www.mille.org/links.html) lista docenas de enlaces en la Red referentes al milenarismo. 